\title{
Association Between Neck Circumference and Poor Outcome in Spontaneous Intracerebral Hemorrhage Patients: A Prospective Observational Study.
}

\section{Yujian Li}

Sichuan University West China Hospital

Huiqing Zhou

Fourth People's Hospital of Sichuan Province

\section{Xiang Yang}

Sichuan University West China Hospital

Jun Zheng

Sichuan University West China Hospital

\section{Fan Zhang}

Sichuan University West China Hospital

\section{Mangmang $\mathrm{Xu}$}

Sichuan University West China Hospital

Hao Li ( $\nabla$ lhmed514@163.com )

Sichuan University West China Hospital

\section{Research article}

Keywords: Intracerebral hemorrhage, Neck circumference, Obesity, Prognosis

Posted Date: July 2nd, 2020

DOl: https://doi.org/10.21203/rs.3.rs-38306/v1

License: (c) (1) This work is licensed under a Creative Commons Attribution 4.0 International License. Read Full License 


\section{Abstract}

Background: Obesity is one of the major risk factors of intracerebral hemorrhage (ICH). Neck circumference (NC) is an indicator of obesity, and little is known about the role of NC in patients with ICH. This study aimed to assess the association between $\mathrm{NC}$ and functional outcome in ICH patients.

Methods: We prospectively analyzed data of $\mathrm{ICH}$ patients who received treatment at our institution from January 2018 to November 2019. Patients were categorized as two groups according to 180-day Modified Rankin Scale (MRS) score. Univariate and multivariate analyses were performed to assess whether $\mathrm{NC}$ was associated with poor outcome in ICH patients. Receiver operating characteristic (ROC) curve analysis was performed to manifest the significance of $\mathrm{NC}$ in predicting the functional outcome of $\mathrm{ICH}$ patients.

Results: A total of 312 patients were enrolled in our study. Multivariate logistic regression analysis indicated that NC was an independent predictor of 180-day poor functional outcome (odds ratio [OR] = $1.205,95 \%$ confidence interval $[\mathrm{Cl}]: 1.075-1.350, p=0.001)$. ROC analysis revealed that NC could predict poor functional outcome at 6 months.

Conclusion: $\mathrm{NC}$ is an independent predictor of unfavorable functional outcome at 6 months in ICH patients.

\section{Background}

Spontaneous intracerebral hemorrhage $(\mathrm{ICH})$ is a devastating healthcare event accounting for $10-15 \%$ of all strokes [1, 2], which has the characteristics of high mortality and morbidity and limited treatment options [3]. Obesity is one of the major risk factors of stroke [4], and is associated with increased morbidity and mortality in the general population $[5,6]$. However, obesity appears to have a survival advantage in patients with certain diseases including heart failure, coronary artery disease, and chronic kidney disease [7-9]. In addition, recent studies has linked this phenomenon, known as the "obesity paradox", to ICH $[10,11]$.

Body mass index (BMI) was an indicator that most commonly used to assess obesity. Whereas, previous studies have showed that neck circumference (NC) could be used as a simple, feasible and stable evaluation index because it is not easily affected by eating or body position [12,13]. In addition, NC is related to oropharyngeal fat infiltration, narrowing the upper respiratory tract [14]. However, little is known about the role of $\mathrm{NC}$ in patients with $\mathrm{ICH}$. The purpose of this study was to explore the relationship between the $\mathrm{NC}$ and the prognosis of $\mathrm{ICH}$.

\section{Methods}

\section{Study design}


This is a single-centre prospective study. We identified all the patients with $\mathrm{ICH}$ visited to West China hospital from January 2018 to November 2019. Informed consent was obtained from all patients or family members. All procedures in the study were approved by the Ethics Committee of the West China Hospital of Sichuan University (Sichaun, China).

\section{Patients}

We defined inclusion criteria as follows: 1) A diagnosis of intracranial hemorrhage by computed tomography (CT); 2) Blood routine examination and laboratorial tests were conducted within 24 hours after admission; 3 ) $\geq 18$ years. Patients who met the following criteria were excluded: 1 ) that ICH was attributable to aneurysm, arteriovenous malformation or moyamoya disease; 2) that ICH was attributable to acute cerebral infarction, thrombolysis of cerebral or myocardial infarction; 3) patients with prior systemic diseases such as immunological disease, neurological disease, recent infectious disease, severe hepatic, renal dysfunction and coagulation dysfunction. 4) patients with isolated intraventricular hemorrhage; 5) patients with a history of neck surgery.

\section{Clinical and laboratory parameters.}

Baseline clinical and demographic parameters were collected at hospital arrival, including NC, BMI, HNR (height-to-NC ratio), age, sex, medical history, Glasgow Coma Scale (GCS) score on admission, blood pressure, cigarette consumption and alcohol use, history of stroke, medical history of hypertension, diabetes mellitus, and history of endotracheal intubation and tracheotomy.

Laboratorial variables were also recorded including white blood cells (WBC), platelet, blood glucose, cholesterol, high density lipoprotein cholesterol (HDL-C), low density lipoprotein cholesterol (LDL-C). The $\mathrm{NC}(\mathrm{cm})$ was taken to the nearest $1 \mathrm{~mm}$, using plastic tape measure. It was taken in a plane as horizontal as possible, at a point just below the larynx (thyroid cartilage) and perpendicular to the long axis of the neck (the tape line in front of the neck at the same height as the tape line in the back of the neck). Two reviewers independently estimated the values of NC. Any disagreement between the two reviewers was solved by the consensus. Height $(\mathrm{m})$ and weight $(\mathrm{kg})$ were measured at the bed side by trained staff on admission using a measure and a digital weight scale, respectively, and BMI $\left(\mathrm{kg} / \mathrm{m}^{2}\right)$ was calculated as standard. Admission HNR was calculated as the ratio of the height to the NC.

Radiological results collected from head CT within $24 \mathrm{~h}$ after admission to hospital included hematoma location, hematoma size, presence of Intraventricular hemorrhage (IVH). Hematoma volume was measured by $A B C / 2$ method as described previously [15]. Two reviewers independently estimated all the head CT scans. Any disagreement between the two reviewers was solved by the consensus.

The functional outcome was assessed by 180-day MRS score by telephone or outpatient visiting. MRS score $\geq 3$ was defined as unfavorable outcome including severe disability, persistent vegetative state, as well as death.

\section{Statistical analysis.}


All the baseline characteristics including clinical variables, laboratorial parameters and radiological data were compared between patients with poor outcome and with favorable outcome. Continuous variables were expressed as mean \pm standard deviation or median with interquartile range (IQR) for normal distribution and non-normal distribution, respectively, whereas categorical variables were expressed as frequency and percentage. Univariate analyses were conducted by independent t test or Mann-Whitney $U$ test or Chi-square $\left(\chi^{2}\right)$ test or Fisher's exact test. Independent $t$ test or Mann-Whitney $U$ test were applied to compare continuous variables. Chi-square $\left(\chi^{2}\right)$ test or Fisher's exact test were conducted to compare categorical data. Variables significant at $p<0.20$ level in the univariate analysis were retained in the multivariate model. For interpretation purposes, some variables were classed as follows: GCS score as "13-15 points", "9-12 points" and "3-8 points"; and hematoma location as "lobe", "basal ganglia", "thalamus", "cerebellum" and "brainstem". Receiver operating characteristic (ROC) analysis was performed to indicate the predictive value of $\mathrm{NC}$ for the functional outcome of $\mathrm{ICH}$ patients. The cut-off value of NC was decided by Youden index from the ROC curve. A value of $p<0.05$ was considered as statistical significant. All the above-mentioned statistical analyses were performed by SPSS version 21.0 (SPSS, Chicago, IL, USA).

\section{Results}

From January 2018 to November 2019, 312 consecutive patients (229 males and 83 females) with spontaneous ICH who met the inclusive criteria were enrolled in this prospective study, the lost rate of follow up was $2 \%$ (7/367, Fig. 1).

The univariate analysis shown that patients with poor functional outcome at 6 months had higher NC ( $p$ $=0.007)$, higher HNR $(p=0.015)$, higher hematoma size $(p<0.001)$, higher WBC count $(p<0.001)$, higher blood glucose level $(p=0.005)$; and had lower age $(p=0.036)$, lower GCS score on admission $(p<0.001)$. On the side, the proportion of patients with IVH (31.7\% versus $50.8 \%, p=0.001)$, endotracheal intubation $(26.8 \%$ versus $67.7 \%, p<0.001)$ and tracheotomy $(9.8 \%$ versus $27.0 \%, p<0.001)$ were higher in the poor outcome group, as well as the patients with basal ganglia hemorrhage ( $40.7 \%$ versus $55.0 \%)$ and brainstem hemorrhage (13.0\% versus $25.4 \%)$ [Table 1]. The multivariate analysis indicated that NC (OR $=$ $1.205,95 \% \mathrm{Cl}: 1.075-1.350, \mathrm{p}=0.001), \mathrm{BMI}(\mathrm{OR}=0.829,95 \% \mathrm{Cl}: 0.722-0.953, \mathrm{p}=0.009), \mathrm{GCS}(9-12$ points) [OR $=4.139,95 \% \mathrm{Cl}: 1.912-8.960, p<0.001]$, GCS (3-8 points) [OR $=57.537,95 \% \mathrm{Cl}: 15.725-$ $210.526, p<0.001]$, hematoma size $(\mathrm{OR}=1.062,95 \% \mathrm{Cl}: 1.034-1.092, \mathrm{p}<0.001)$, basal ganglia hemorrhage $(O R=6.300,95 \% \mathrm{Cl}: 2.285-17.375, \mathrm{p}<0.001)$ and brainstem hemorrhage $(O R=16.223,95 \%$ Cl: $3.226-81.572, p=0.001)$ were significantly correlated with poor functional outcome at 6 months (Table 2). ROC curve analysis showed that NC could predict poor functional outcome with an area under the curve of 0.591 ( $95 \% \mathrm{Cl}: 0.527-0.655, p=0.007$, Fig. 2). The value of $39.45 \mathrm{~cm}$ for NC was the best cut-off in predicting function outcome of $\mathrm{ICH}$ patients according to Youden index and we found that the proportion of poor outcome in patients with $\mathrm{NC} \geq 39.45 \mathrm{~cm}$ and patients with $\mathrm{NC}<39.45 \mathrm{~cm}$ was $63.1 \%$ and $55.1 \%$, respectively. 
Table 1

Clinical characteristics related to 180-day outcome in patients with ICH

\begin{tabular}{|c|c|c|c|}
\hline Characteristic & $\begin{array}{l}\text { favorable outcome } \\
(n=123)\end{array}$ & $\begin{array}{l}\text { poor outcome } \\
(n=189)\end{array}$ & p-Value \\
\hline $\mathrm{NC}(\mathrm{cm})$ & $41.01 \pm 4.79$ & $42.46 \pm 4.68$ & $0.007 *$ \\
\hline $\mathrm{BMI}\left(\mathrm{kg} / \mathrm{m}^{2}\right)$ & $25.46 \pm 4.29$ & $26.14 \pm 3.75$ & 0.142 \\
\hline HNR & $4.03 \pm 0.41$ & $3.92 \pm 0.37$ & $0.015^{*}$ \\
\hline Age(years) & $61(49,70)$ & $56(46,67)$ & $0.036^{*}$ \\
\hline Sex (male) & $86(69.9 \%)$ & $143(75.7 \%)$ & 0.262 \\
\hline Hypertension & $99(80.5 \%)$ & 164(86.8\%) & 0.136 \\
\hline Diabetes mellitus & $12(9.8 \%)$ & $9(4.8 \%)$ & 0.085 \\
\hline Prior stroke & $3(2.4 \%)$ & $10(5.3 \%)$ & 0.260 \\
\hline Smoking & $40(32.5 \%)$ & $52(27.5 \%)$ & 0.343 \\
\hline Drinking & $26(21.1 \%)$ & $54(28.6 \%)$ & 0.142 \\
\hline $\mathrm{SBP}(\mathrm{mmHg})$ & $161.70 \pm 29.90$ & $165.74 \pm 27.98$ & 0.207 \\
\hline $\mathrm{DBP}(\mathrm{mmHg})$ & $94.58 \pm 17.96$ & $98.43 \pm 17.74$ & 0.063 \\
\hline GCS score on admission & - & - & $<0.001 * *$ \\
\hline $13-15$ & $80(65.0 \%)$ & $27(14.3 \%)$ & - \\
\hline $9-12$ & $38(30.9 \%)$ & $58(30.7 \%)$ & - \\
\hline $3-8$ & $5(4.1 \%)$ & $104(55.0 \%)$ & - \\
\hline $\mathrm{ICH}$ location & - & - & $<0.001 * *$ \\
\hline Lobe & $32(26.0 \%)$ & $17(9.0 \%)$ & - \\
\hline Basal ganglia & $50(40.7 \%)$ & 104(55.0\%) & - \\
\hline Thalamus & $18(14.6 \%)$ & $16(8.5 \%)$ & - \\
\hline Cerebellum & $7(5.7 \%)$ & $4(2.1 \%)$ & - \\
\hline Brainstem & 16(13.0\%) & $48(25.4 \%)$ & - \\
\hline Hematoma size $(\mathrm{ml})$ & $15.0(6.2,27.3)$ & $31.9(15.3,55.8)$ & $<0.001 * *$ \\
\hline \multicolumn{4}{|c|}{$\begin{array}{l}\text { Data are expressed as } \mathrm{n}(\%), \text { mean } \pm \text { standard deviation, or median (interquartile range), as } \\
\text { appropriate.*P }<0.05,{ }^{*} \mathrm{P}<0.001 \text {. ICH, intracerebral hemorrhage; NC, neck circumference; BMI, body } \\
\text { mass index; } \mathrm{HNR} \text {, height-to-NC ratio; SBP, systolic blood pressure; DBP, diastolic blood pressure; GCS, } \\
\text { Glasgow Coma Scale; IVH, intraventricular hemorrhage; WBC, white blood cells; HDL-C, high density } \\
\text { lipoprotein cholesterol; LDL-C, low density lipoprotein cholesterol. }\end{array}$} \\
\hline
\end{tabular}




\begin{tabular}{|c|c|c|c|}
\hline Characteristic & $\begin{array}{l}\text { favorable outcome } \\
(n=123)\end{array}$ & $\begin{array}{l}\text { poor outcome } \\
(n=189)\end{array}$ & p-Value \\
\hline Presence of IVH & $39(31.7 \%)$ & $96(50.8 \%)$ & $0.001 *$ \\
\hline Endotracheal intubation & $33(26.8 \%)$ & $128(67.7 \%)$ & $<0.001 * *$ \\
\hline Tracheotomy & $12(9.8 \%)$ & $51(27.0 \%)$ & $<0.001 * *$ \\
\hline WBC, $\times 10^{9}$ & $9.98 \pm 3.88$ & $12.39 \pm 4.09$ & $<0.001 *$ \\
\hline Platelet, $x 10^{9}$ & $173.98 \pm 60.66$ & $181.21 \pm 69.63$ & 0.347 \\
\hline Blood glucose (mmol/L) & $7.75 \pm 2.89$ & $8.68 \pm 2.75$ & $0.005^{*}$ \\
\hline Cholesterol (mmol/L) & $4.47 \pm 1.08$ & $4.43 \pm 1.19$ & 0.758 \\
\hline $\mathrm{HDL}-\mathrm{C}(\mathrm{mmol} / \mathrm{L})$ & $1.35 \pm 0.43$ & $1.32 \pm 0.52$ & 0.568 \\
\hline LDL-C (mmol/L) & $2.61 \pm 0.77$ & $2.59 \pm 0.98$ & 0.854 \\
\hline \multicolumn{4}{|c|}{$\begin{array}{l}\text { Data are expressed as } n(\%) \text {, mean } \pm \text { standard deviation, or median (interquartile range), as } \\
\text { appropriate.*P }<0.05,{ }^{*} \mathrm{P}<0.001 \text {. ICH, intracerebral hemorrhage; NC, neck circumference; BMI, body } \\
\text { mass index; HNR, height-to-NC ratio; SBP, systolic blood pressure; DBP, diastolic blood pressure; GCS, } \\
\text { Glasgow Coma Scale; IVH, intraventricular hemorrhage; WBC, white blood cells; HDL-C, high density } \\
\text { lipoprotein cholesterol; LDL-C, low density lipoprotein cholesterol. }\end{array}$} \\
\hline
\end{tabular}


Table 2

Multivariate analysis of predictors for poor outcome at 6 months

\begin{tabular}{|c|c|c|}
\hline Predictors & OR $(95 \% \mathrm{Cl})$ & P Value \\
\hline NC (per 1 cm increase) & $1.205(1.075-1.350)$ & $0.001 *$ \\
\hline $\mathrm{BMI}\left(\right.$ per $1 \mathrm{~kg} / \mathrm{m}^{2}$ increase $)$ & $0.829(0.722-0.953)$ & $0.009 *$ \\
\hline GCS score on admission & - & - \\
\hline GCS(13-15 points) & Reference & - \\
\hline GCS(9-12 points) & $4.139(1.912-8.960)$ & $<0.001 * *$ \\
\hline GCS(3-8 points) & $57.537(15.725-210.526)$ & $<0.001 * *$ \\
\hline $\mathrm{ICH}$ location & - & - \\
\hline Lobe & Reference & - \\
\hline Basal ganglia & $6.300(2.285-17.375)$ & $<0.001 * *$ \\
\hline Thalamus & $3,751(0.856-16.444)$ & 0.080 \\
\hline Cerebellum & $0.363(0.045-2.893)$ & 0.338 \\
\hline Brainstem & 16.223(3.226-81.572) & $0.001 *$ \\
\hline Hematoma size (per $1 \mathrm{ml}$ increase) & $1.062(1.034-1.092)$ & $<0.001 * *$ \\
\hline Presence of IVH & $3.176(1.476-6.834)$ & $0.003^{*}$ \\
\hline \multicolumn{3}{|c|}{$\begin{array}{l}\text { Adjustment by diastolic blood pressure, age, hypertension, diabetes mellitus, drinking, endotracheal } \\
\text { intubation, tracheotomy, white blood cells and blood glucose. }{ }^{*}<0.05 \text {, } * * \mathrm{P}<0.001 \text {. NC, neck } \\
\text { circumference; BMl, body mass index; GCS, Glasgow Coma Scale; ICH, intracerebral hemorrhage; IVH } \\
\text { intraventricular hemorrhage; OR: odds ratio, Cl: confidence interval. }\end{array}$} \\
\hline
\end{tabular}

\section{Discussion}

To the best of our knowledge, this is the first study that focused on the NC in patients with ICH. We found that $\mathrm{NC}$ was an independent risk factor for poor prognosis of $\mathrm{ICH}$, and $\mathrm{BMI}$ was independently inversely associated with poor outcome in ICH patients. NC is an indicator of obesity that reflects human health [16-21]. Previous studies have shown that NC is associated with an increased risk of hypertension [18], diabetes $[17,21]$ and metabolic syndrome [19]. NC is also found to be associated with congestive heart failure incidence and coronary heart disease mortality [20]. However, researches regarding the association between $\mathrm{NC}$ and $\mathrm{ICH}$ were limited.

According to the "obesity paradox", obese and overweight stroke patients had favorable prognosis than those with a normal or lower BMI [22-24]. Consistent with these findings, we found that BMI was independently inversely associated with poor outcome in ICH patients. Interestingly, we also found a contradictory relationship between $\mathrm{BMI}$ and $\mathrm{NC}$ in predicting the prognosis of $\mathrm{ICH}$. One possible 
explanation for the paradoxical phenomenon may be that the two obesity indicators are different in fat distribution. BMI only reflects the total body obesity and NC represents an alternative method for measuring upper body subcutaneous fat [25]. Moreover, it had been demonstrated that NC was associated with oropharyngeal fatty infiltration, which narrows the upper airway, resulting in obstructive sleep apnea (OSA) [14].

A retrospective study found that the larger the $\mathrm{NC}$ ( $\geq 43.2 \mathrm{~cm}$ in men and $\geq 36.8 \mathrm{~cm}$ in women), the higher the incidence of obstructive sleep apnea was 2.52 times in men and 3.13 times in women [26]. And, it was reported that compared with BMI, NC better explained the change in apnea-hypopnea index in morbidity obese women $(n=115)$ in the predictive model [27]. OSA had been reported to be associated with $\mathrm{ICH}$. The hypoxia and hemodynamic responses associated with OSA may predispose to stroke [28]. Moreover, OSA was associated with the development of perihematoma edema [29], which may cause poor outcome after ICH [30-32]. Several mechanisms may have influence on the development of encephaledema after ICH. The early stage of cerebral edema occurs in the first few hours after ICH, which involves hydrostatic pressure induced by formation of hematoma and retraction of clot, the second phase, caused by production of thrombin and activation of the coagulation cascade, occurs within the first 24 hours, and the delayed stage involves in red blood cells hemolysis and hemoglobin-induced toxicity $[33,34]$. The sizes of perihematoma edema have also been related to several factors such as the level of serum ferritin and increased matrix metalloproteinase-9 activity, which is an important enzyme for the blood brain barrier remodeling and perihematoma edema development [35-38].

Due to a momentary cessation of breathing, OSA patients with this disorder have repeated episodes of hypoxia/reoxygenation, promoting systemic oxidative stress, clotting cascade activation, inflammation, and damaged repair competence of the vascular endothelium [39]. Thus, through the above several pathways, OSA may have a role in the generation of perihematoma edema. Moreover, OSA has also been demonstrated to be associated with the enhanced activity of matrix metalloproteinase- 9 . Therefore, it is reasonable to believe that the association between OSA and perihematoma edema is biologically plausible.

Mechanical ventilation after tracheotomy or endotracheal intubation may prevent OSA-related hypoxia. However, a previous study have reported that in acute spontaneous ICH patients, endotracheal intubation and mechanical ventilation were associated with increased risk of hospital-acquired pneumonia and inhospital mortality [40]. Consistently, in the present study, we found that the proportions of patients with tracheotomy and endotracheal intubation were higher in the poor outcome group. The reason may be that the hematoma volume in $\mathrm{ICH}$ patients with tracheotomy or endotracheal intubation was larger than patients without tracheotomy or endotracheal intubation, which suggested more severe condition and poorer prognosis.

In addition, previous studies have shown that NC was associated with an increased risk of hypertension [18], diabetes [17, 21] and metabolic syndrome [19], which also played a role in the occurrence and development of ICH [41-43]. Furthermore, Pezzini et al. found that obesity, mainly through its indirect 
effect on hypertension and obesity-related complication, played a role in ICH [44]. Taken together, NC should not be overlooked in evaluating ICH patients.

However, our study still has several limitations. First, this study collected data from one hospital, with a limited sample size, which may lead to selection bias. Second, NC is one of the factors causing upper respiratory tract stenosis, and the presence of other unmeasured factors will still influence our final conclusion. Third, OSA was not accurately assessed in our study. At last, all the ICH patients were only from West China Hospital, recruiting poor clinical conditions patients usually because of the medical referral system.

\section{Conclusions}

$\mathrm{NC}$ is an independent predictor of unfavorable functional outcome at 6 months. Further experiments are necessary to explore the specific mechanism.

\section{Abbreviations}

Body mass index (BMI); Confidence interval (Cl); Computed tomography (CT); Glasgow Coma Scale (GCS); Diastolic blood pressure (DBP); High density lipoprotein cholesterol (HDL-C); HNR (height-to-NC ratio); Intracerebral hemorrhage (ICH); Interquartile range (IQR); Intraventricular hemorrhage (IVH); Low density lipoprotein cholesterol (LDL-C); Modified Rankin Scale (MRS); Neck circumference (NC); Odds ratio (OR); Receiver operating characteristic (ROC); Systolic blood pressure (SBP); White blood cells (WBC)

\section{Declarations}

\section{Ethics approval and consent to participate}

This study was permitted by the Ethics Committee of the West China Hospital of Sichuan University (Sichuan, China). Written informed consent was sought from all participants, in cases suffered severe disability and were not able to give informed consent, this was obtained from their legally authorized representatives.

\section{Consent for publication}

Not applicable.

\section{Availability of data and materials}

The datasets used or analysed during the current study are available from the corresponding author on reasonable request.

\section{Competing interests}


The authors have no competing of interest to declare.

\section{Funding}

None to report.

\section{Authors' contributions}

YJL, HQZ and XY contributed with conception, design, analyses, interpretation and write-up of the first draft of the manuscript. JZ, MMX and FZ contributed with scientific input, analyses, interpretation and wrote sections of the manuscript. HL contributed with interpretation and scientific input. All authors read and approved the final manuscript.

\section{Acknowledgements}

Not applicable.

\section{Authors' information}

Not applicable.

\section{References}

1. Qureshi Al, Tuhrim S, Broderick JP, et al. Spontaneous intracerebral hemorrhage. N Engl J Med. 2001;344:1450-60.

2. Qureshi Al, Mendelow AD, Hanley DF. Intracerebral haemorrhage. Lancet. 2009;373:1632-44.

3. Broderick J, Connolly S, Feldmann E, et al. Guidelines for the management of spontaneous intracerebral hemorrhage in adults: 2007 update: a guideline from the American Heart Association/American Stroke Association Stroke Council, High Blood Pressure Research Council, and the Quality of Care and Outcomes in Research Interdisciplinary Working Group. Stroke. 2007;38:2001-23.

4. Strazzullo P, D'Elia L, Cairella G, et al. Excess body weight and incidence of stroke: meta-analysis of prospective studies with 2 million participants. Stroke. 2010;41:e418-26.

5. Whitlock G, Lewington S, Sherliker P, et al. Body-mass index and cause-specific mortality in 900000 adults: collaborative analyses of 57 prospective studies. Lancet. 2009;373:1083-96.

6. Pischon T, Boeing H, Hoffmann K, et al. General and abdominal adiposity and risk of death in Europe. N Engl J Med. 2008;359:2105-20.

7. Schmidt D, Salahudeen A. The obesity-survival paradox in hemodialysis patients: why do overweight hemodialysis patients live longer? Nutr Clin Pract. 2007;22:11-5.

8. Romero-Corral A, Montori VM, Somers VK, et al. Association of bodyweight with total mortality and with cardiovascular events in coronary artery disease: a systematic review of cohort studies. Lancet. 2006;368:666-78. 
9. Horwich TB, Fonarow GC, Hamilton MA, et al. The relationship between obesity and mortality in patients with heart failure. J Am Coll Cardiol. 2001;38:789-95.

10. Dangayach NS, Grewal HS, De Marchis GM, et al. Does the obesity paradox predict functional outcome in intracerebral hemorrhage? J Neurosurg. 2018;129:1125-9.

11. Sun $W$, Xian $Y$, Huang $Y$, et al. Obesity is associated with better survival and functional outcome after acute intracerebral hemorrhage. J Neurol Sci. 2016;370:140-4.

12. Laakso M, Matilainen V, Keinänen-Kiukaanniemi S. Association of neck circumference with insulin resistance-related factors. Int J Obes $\mathrm{i}^{1} / 4^{2}$ elat Metab Disord. 2002;26:873-5.

13. Onat A, Avci GS, Barlan MM, et al. Measures of abdominal obesity assessed for visceral adiposity and relation to coronary risk. Int J Obes $\mathrm{I}^{1} / 4^{2}$ elat Metab Disord. 2004;28:1018-25.

14. Godoy IR, Martinez-Salazar EL, Eajazi A, et al. Fat accumulation in the tongue is associated with male gender, abnormal upper airway patency and whole-body adiposity. Metab Clin Exp. 2016;65:1657-63.

15. Webb AJ, Ullman NL, Morgan TC, et al. Accuracy of the ABC/2 Score for Intracerebral Hemorrhage: Systematic Review and Analysis of MISTIE, CLEAR-IVH, and CLEAR III. Stroke. 2015;46:2470-6.

16. Kwon HM, Park JH, Park JH, et al. Visceral Fat Is an Independent Predictor of Cerebral Microbleeds in Neurologically Healthy People. Cerebrovasc Dis. 2016;42:90-6.

17. Yang GR, Yuan SY, Fu HJ, et al. Neck circumference positively related with central obesity, overweight, and metabolic syndrome in Chinese subjects with type 2 diabetes: Beijing Community Diabetes Study 4. Diabetes Care. 2010;33:2465-7.

18. Kuciene R, Dulskiene V, Medzioniene J. Association of neck circumference and high blood pressure in children and adolescents: a case-control study. BMC Pediatr. 2015;15:127.

19. Alzeidan R, Fayed A, Hersi AS, et al. Performance of neck circumference to predict obesity and metabolic syndrome among adult Saudis: a cross-sectional study. BMC Obes. 2019;6:13.

20. Zhang J, Guo Q, Peng L, et al. The association of neck circumference with incident congestive heart failure and coronary heart disease mortality in a community-based population with or without sleepdisordered breathing. BMC Cardiovasc Disord. 2018;18:108.

21. Anothaisintawee T, Sansanayudh N, Thamakaison S, et al. Neck Circumference as an Anthropometric Indicator of Central Obesity in Patients with Prediabetes: A Cross-Sectional Study. Biomed Res Int. 2019; 2019: 4808541.

22. Doehner W, Schenkel J, Anker SD, et al. Overweight and obesity are associated with improved survival, functional outcome, and stroke recurrence after acute stroke or transient ischaemic attack: observations from the TEMPiS trial. Eur Heart J. 2013;34:268-77.

23. Kim BJ, Lee SH, Ryu WS, et al. Paradoxical longevity in obese patients with intracerebral hemorrhage. Neurology. 2011;76:567-73.

24. Vemmos K, Ntaios G, Spengos K, et al. Association between obesity and mortality after acute firstever stroke: the obesity-stroke paradox. Stroke. 2011;42:30-6. 
25. Salmanroghani H, Salmanroghani R, Nourian M, et al. Evaluation of neck circumference as an easy and reliable predictor for non-alcoholic fatty liver disease. Turk J Gastroenterol. 2019;30:163-70.

26. Earl DE, Lakhani SS, Loriaux DB, et al. Predictors of moderate to severe obstructive sleep apnea: identification of sex differences. Sleep Breath. 2019;23:1151-8.

27. Gasa M, López-Padrós C, Monasterio C, et al. Anthropometrical phenotypes are important when explaining obstructive sleep apnea in female bariatric cohorts. J Sleep Res. 2019;28:e12830.

28. Dyken ME, Somers VK, Yamada T, et al. Investigating the relationship between stroke and obstructive sleep apnea. Stroke. 1996;27:401-7.

29. Pontes-Neto OM, Fernandes RM, Sander HH, et al. Obstructive sleep apnea is frequent in patients with hypertensive intracerebral hemorrhage and is related to perihematoma edema. Cerebrovasc Dis. 2010;29:36-42.

30. Urday S, Beslow LA, Dai F, et al. Rate of Perihematomal Edema Expansion Predicts Outcome After Intracerebral Hemorrhage. Crit Care Med. 2016;44:790-7.

31. Grunwald Z, Beslow LA, Urday S, et al. Perihematomal Edema Expansion Rates and Patient Outcomes in Deep and Lobar Intracerebral Hemorrhage. Neurocrit Care. 2017;26:205-12.

32. Yang J, Arima H, Wu G, et al. Prognostic significance of perihematomal edema in acute intracerebral hemorrhage: pooled analysis from the intensive blood pressure reduction in acute cerebral hemorrhage trial studies. Stroke. 2015;46:1009-13.

33. Xi G, Keep RF, Hoff JT. Pathophysiology of brain edema formation. Neurosurg Clin N Am. 2002;13:371-83.

34. Gebel JM, Jauch EC, Brott TG, et al. Relative edema volume is a predictor of outcome in patients with hyperacute spontaneous intracerebral hemorrhage. Stroke. 2002;33:2636-41.

35. Abilleira S, Montaner J, Molina CA, et al. Matrix metalloproteinase-9 concentration after spontaneous intracerebral hemorrhage. J Neurosurg. 2003;99:65-70.

36. Alvarez-Sabín J, Delgado P, Abilleira S, et al. Temporal profile of matrix metalloproteinases and their inhibitors after spontaneous intracerebral hemorrhage: relationship to clinical and radiological outcome. Stroke. 2004;35:1316-22.

37. Mehdiratta M, Kumar S, Hackney D, et al. Association between serum ferritin level and perihematoma edema volume in patients with spontaneous intracerebral hemorrhage. Stroke. 2008;39:1165-70.

38. Lou M, Lieb K, Selim M. The relationship between hematoma iron content and perihematoma edema: an MRI study. Cerebrovasc Dis. 2009;27:266-71.

39. Jelic S, Le Jemtel TH. Inflammation, oxidative stress, and the vascular endothelium in obstructive sleep apnea. Trends Cardiovasc Med. 2008;18:253-60.

40. Lioutas VA, Marchina S, Caplan LR, et al. Endotracheal Intubation and In-Hospital Mortality after Intracerebral Hemorrhage. Cerebrovasc Dis. 2018;45:270-8.

41. Boulanger M, Poon MT, Wild SH, et al. Association between diabetes mellitus and the occurrence and outcome of intracerebral hemorrhage. Neurology. 2016;87:870-8. 
42. Mitaki S, Takayoshi H, Nakagawa T, et al. Metabolic syndrome is associated with incidence of deep cerebral microbleeds. PLoS ONE. 2018;13:e0194182.

43. Chung PW, Kim JT, Sanossian N, et al. Association Between Hyperacute Stage Blood Pressure Variability and Outcome in Patients With Spontaneous Intracerebral Hemorrhage. Stroke. 2018;49:348-54.

44. Pezzini $A$, Grassi $M$, Paciaroni $M$, et al. Obesity and the risk of intracerebral hemorrhage: the multicenter study on cerebral hemorrhage in Italy. Stroke. 2013;44:1584-9.

\section{Figures}

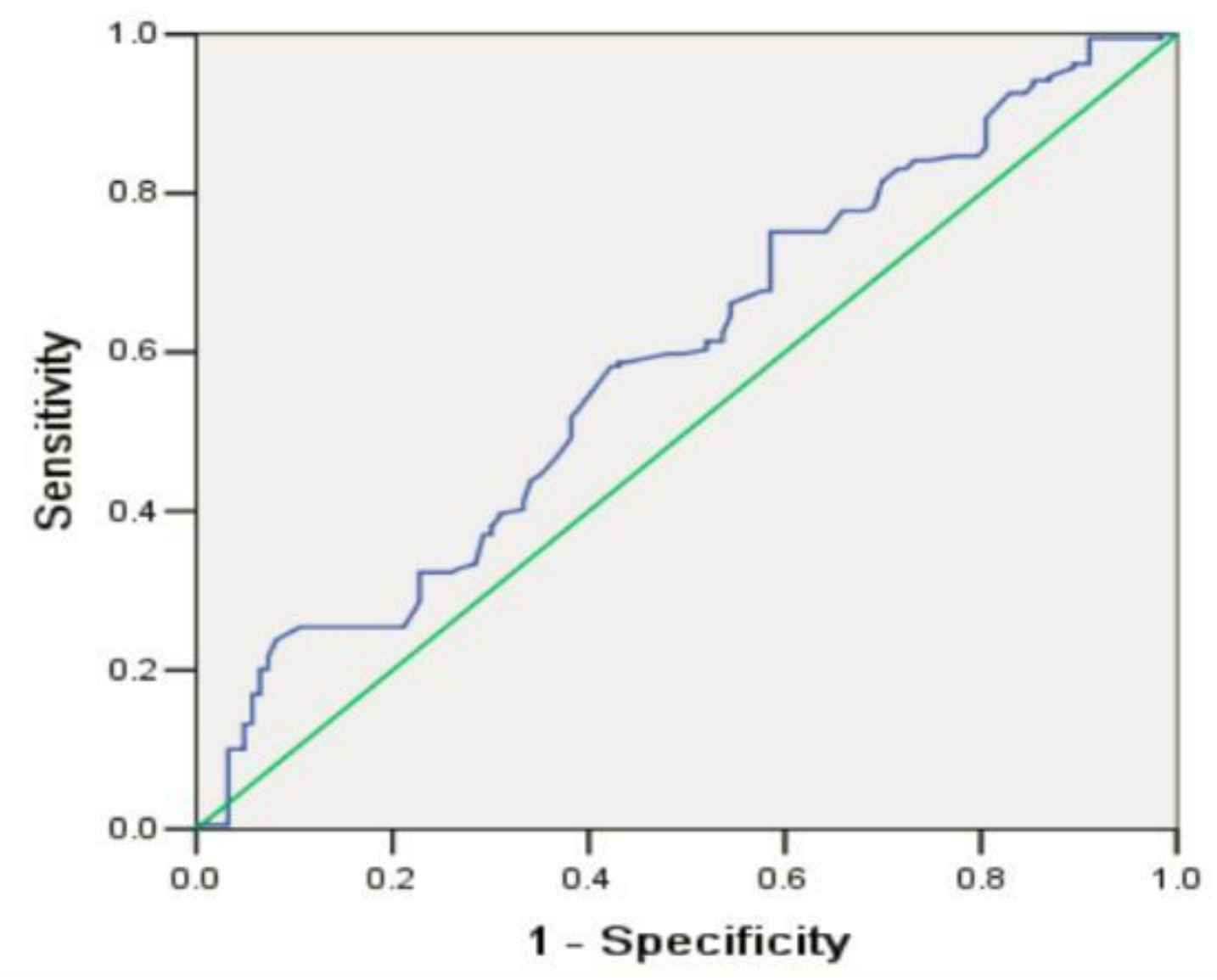

Figure 1

Flow diagram of patients with spontaneous intracerebral hemorrhage. 


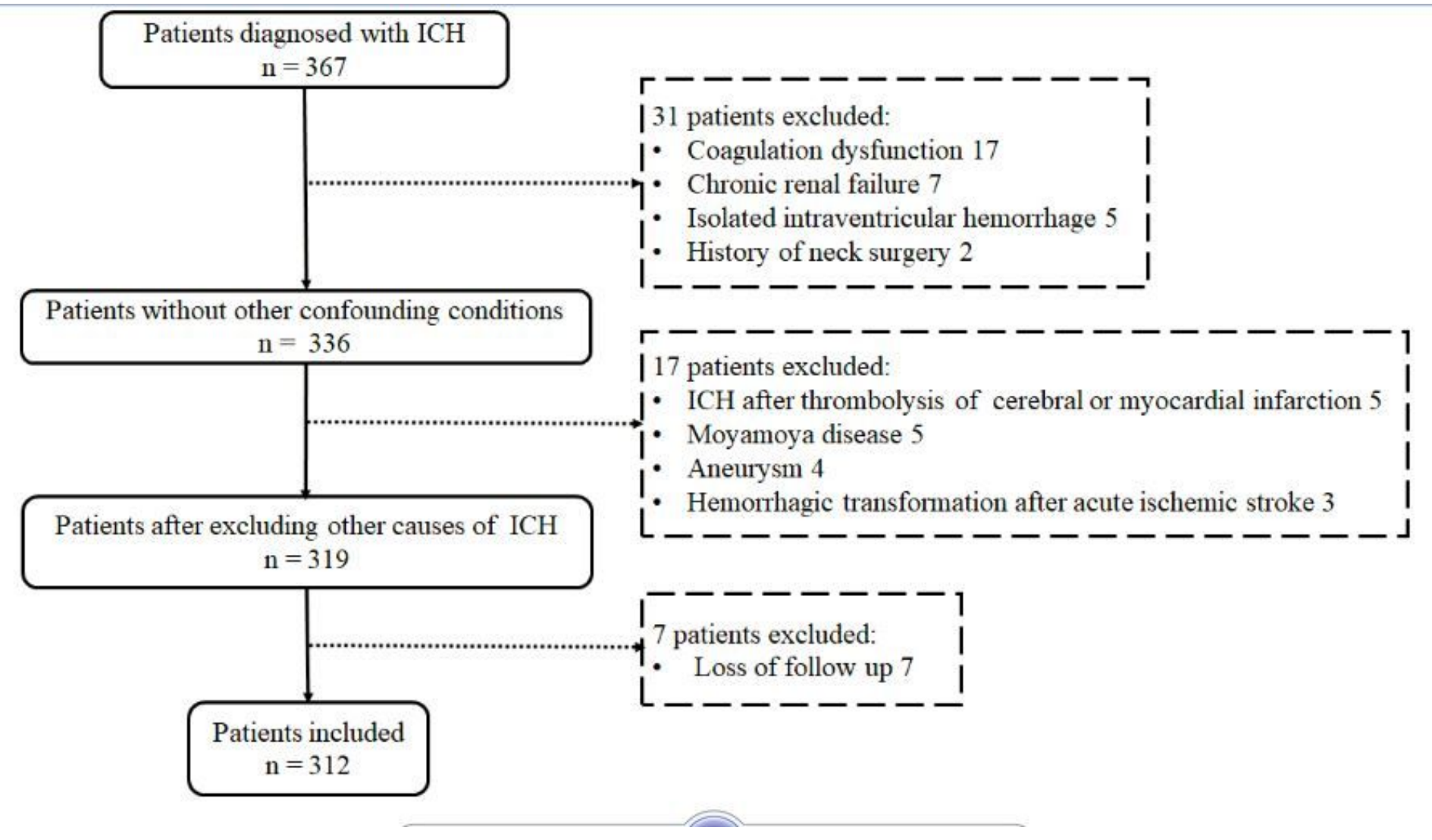

Figure 2

Receiver operating characteristic curve for the predictive value of $\mathrm{NC}$ for functional outcome in ICH patients at 6 months. 